\title{
Survey-Based Assessment of Design Skill Development in Engineering Project Courses
}

\author{
Brian Frank, David Strong \\ Queen's University \\ brian.frank@queensu.ca, strongd@appsci.queensu.ca
}

\begin{abstract}
A pilot of a paper-based assessment tool of design skill is presented. The tool is used to assess the development of skills before and after a first year design experience, and before and after a third year multidisciplinary course in design tools and methodology. The tool is an open-ended survey that may be administered quickly and assessed using a simple rubric. Significant improvements were found over the term of the first year course in the areas of problem definition and testing; improvements were observed in the categories of Conceptual Design, Preliminary Design, and Detailed Design in the third year course. Ideas for future improvement are discussed.
\end{abstract}

\section{Introduction}

Engineering educators are increasingly recognizing the importance of developing design skills in undergraduate engineering students. It is critical, for both accreditation and quality assurance purposes, that engineering educators be able to assess the design skills of students. This assessment could take many forms, as will be discussed in Section 2.

The objective of this project is to:

- Develop a tool to assess the impact of design courses on students' ability to apply design methodology and tools.

- Assess the validity and reliability of the tool.

- Using the tool, assess the impact of design courses on student understanding of engineering design process.

This paper presents the preliminary outcomes of this project which was piloted in the 2007/2008 academic year at Queen's University.

\section{Assessing Design Skill}

Assessing engineering design skills is challenging, as the problems are generally ill-defined, open-ended, and can be approached in many ways. However, there are some generally accepted principles for effective engineering design process.

Previous work on assessing engineering design skills has taken a variety of approaches. These include:

- using audio and video recordings of students doing design activities $[1,2]$

- using a computer-based simulation of a design activity [3]

- asking students to rank, from a provided list, the types of information they would gather to complete the design of a playground [4]

- Closed-ended questionnaire that required students to identify strengths and weaknesses of a proposed process, and to explain rationale for the decision [5]. The results were scored using an analytical rubric which allowed the instructor the ability to identify areas of misunderstanding.

This paper presents the development of an open-ended survey to assess students' ability to apply design process simple design problems It can be delivered to large number of students in a relatively small period of time, and used to assess development of design ability over the term of a design course. The activity and scoring are quite simple, allowing the tool to be given by instructors and scored relatively quickly by non-experts in design. The tool assesses only the process used for design, as past work has shown this to be correlated with in successful design [6].

This method was chosen for several reasons. Firstly, although design is primarily a team-based activity, it is very difficult to assess individual knowledge on team project [2,5]. Secondly there is a need for a simple method of assessment that is not time-consuming and can be used to assess development in a range of design courses and throughout an engineering program. The tool should also be able to assess the process of design rather than the ability to complete a particular task. 


\section{Courses Involved in Assessment}

The design survey was piloted in two engineering design project courses at Queen's University. One is a common first year course, APSC-100-Practical Engineering Modules, built around an open-ended team-based design project designed to foster curiosity and an appreciation for the open-ended nature of engineering. The second course, APSC-381-Fundamentals of Design Engineering, is an elective third year multidisciplinary course in design methodology, tools, and practice.

\subsection{APSC-100: Introductory Team Design Project}

In this course three student teams, in sub-teams of 3-5, work on a project under the supervision of (a) an upper year student serving as a project manager, and (b) a faculty sponsor. For many of the projects, an agency partner is also involved. Most of the time in the course is devoted to student-directed work, but there are introductory one-hour workshops on design process, information management, safety, and technical communications [7].

\subsection{APSC-381: Fundamentals of Design Engineering}

Open to students in all engineering disciplines, this course covers engineering design process and tools commonly used in engineering practice from concept to implementation, including professional skills such as project economics, regulatory compliance, and societal considerations. Instruction is reinforced with concurrent multidisciplinary team projects, typically in groups of 4 students. Although topics of instruction include prototyping, design validation, and implementation, students are not required to build and test their projects, although some do, with encouragement.

\section{Design skill survey}

The survey was developed to assess the students' ability to apply a design process to a general open-ended design scenario. The question was deliberately very open-ended, and contained no information that could prompt students. The survey was completed individually without access to other resources under supervised conditions, and students used approximately 10 minutes in APSC-100, and approximately 15 minutes in APSC-381, but the length of time given was determined by time required for the majority of students to complete the task to their satisfaction, rather than a pre-set time.

The survey was given at the beginning ("pre"), and end ("post") of each course, though the scenarios were changed between the beginning and end. In this paper, students completing the survey before and after the two courses will be labelled as shown in Table 1.

Table 1: Four cohorts involved in piloting the design assessment tool.

\begin{tabular}{|l|l|}
\hline \multicolumn{1}{|c|}{ Label } & \multicolumn{1}{c|}{ Criteria } \\
\hline pre100 & $\begin{array}{l}\text { Students in first year design course, before the } \\
\text { start of the project }\end{array}$ \\
\hline post100 & $\begin{array}{l}\text { Students in first year design course, after the } \\
\text { completion of the project }\end{array}$ \\
\hline pre381 & $\begin{array}{l}\text { Students in third year design course, before } \\
\text { the start of the project }\end{array}$ \\
\hline post381 & $\begin{array}{l}\text { Students in third year design course, after the } \\
\text { completion of the project }\end{array}$ \\
\hline
\end{tabular}

The survey was administered in the first class session of APSC-100 and APSC-381, and in the final class of APSC381. The post-survey in APSC-100 was run in the final project team meetings, proctored by the upper year project managers, as there was no class session at the end of the semester to run the survey. The scores on the survey were not used for grading purposes.

The survey instructions are shown in Figure 1. Three scenarios were provided on the pre- and -post surveys. For the pre surveys the options were design of a pre-schooler tricycle, a desk for vision impaired, or a payphone. On the post surveys the options were design of a water catchment tank, a residence for the school for the deaf, or a waterfront trail.

\subsection{Rubric}

A rubric was developed to assess the survey which was derived from the generally accepted steps in engineering design process, and in particular, that which is taught in APSC-381. Each step is broken down into three expected levels of student capability - novice, intermediate, and expert. Key words and phrases are listed for each step and each level, using terminology that is as generic as possible for typical engineering disciplines. As students progress from novice through expert, it is assumed that they will be able to articulate more specifics of design methodology and identify commonly used design tools and techniques.

As indicated previously, the intention was to create a rubric that allowed quick assessment by non-experts in design. This implies analytical (content/order) rather than holistic interpretation of the rubric by the marker. This is contrary to holistic rubrics that are becoming more commonly used in course assessment, such as the Ideas, Connection, Extensions rubric approach adopted for the first year APSC-190-Professional Engineering Skills course at Queen's [8]. In this case, however, since students were asked only to list the steps they would take to ensure a successful design, a holistic approach is not feasible. 


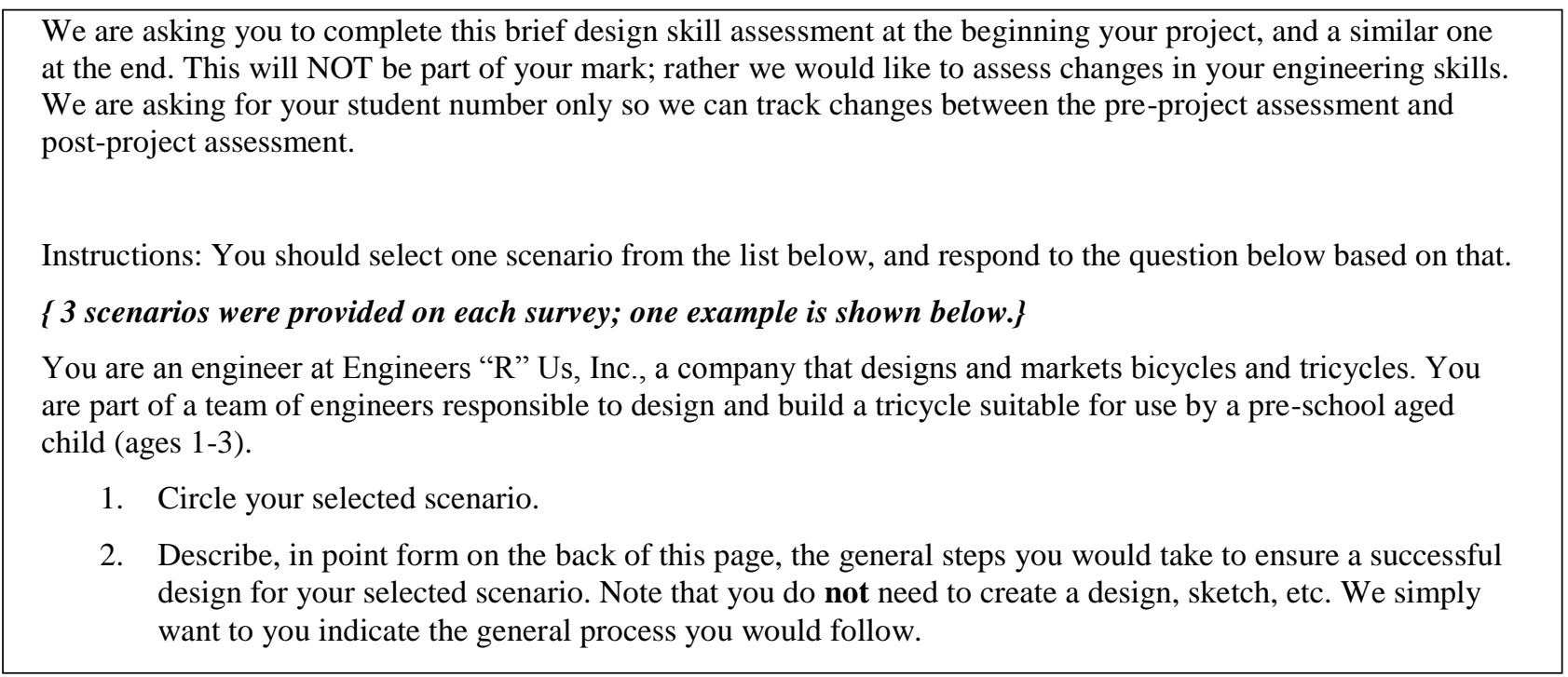

Figure 1: Design skill survey given at the beginning and end of the design courses.

Using the rubric, grades were assigned according to the specific words and phrases recorded in the student survey. If the design steps were significantly out of order, up to 3 marks were deducted, recognizing that parallel activities are often appropriate for some design solutions.

Table 3 shows the rubric developed to assess the students' ability to outline their design process.

\subsection{Rubric scoring}

To test the variability of scores between graders, six skills surveys were picked at random from each of the two course and graded by a design expert (instructor), a recent graduate (who had been enrolled in elective design courses including APSC 381), and an administrative staff member. Comparative grades for each survey initially differed by $+/-30 \%$ in absolute terms, but the grade trends from survey to survey were remarkably consistent.

The results of the initial surveys were discussed amongst the markers, and another set of random samples were graded. In this second set of surveys, not only were the trends consistent, but also the absolute grades were within a much tighter range.

\section{Analysis}

The majority of the surveys have been scored and analyzed. The total score, scores on each of the six major categories on the rubric, and scores of pre100, post100, pre381, and post381 were compared. The standard deviations of four cohorts varied from a minimum of 1.77 (post100) to a maximum of 2.3 (post381).
Table 3 shows the changes in scores among the four cohorts. Paired t-tests (for the comparison of pre/post 100 and pre/post 381) and an unpaired t-test (for the comparison of post100 and pre-381) were used to determine which changes were significant at a $95 \%$ confidence level.

Table 2: Changes in scores. Significant changes at a 95\% confidence level shown in italics.

\begin{tabular}{|l|c|c|c|}
\hline \multicolumn{1}{|c|}{ Step } & $\begin{array}{c}\text { Mean } \\
\text { (post100- } \\
\text { pre100) }\end{array}$ & $\begin{array}{c}\text { Mean } \\
\text { (pre381)-Mean } \\
\text { (post100) }\end{array}$ & $\begin{array}{c}\text { Mean } \\
\text { (post381- } \\
\text { pre381) }\end{array}$ \\
\hline Problem & 0.65 & 0.20 & 0.122 \\
\hline Conceptual & 0 & 0.46 & 0.35 \\
\hline Preliminary & 0.07 & 0.27 & 0.74 \\
\hline Detailed & 0.11 & 0.29 & 0.45 \\
\hline $\begin{array}{l}\text { Validation and } \\
\text { Documentation }\end{array}$ & 0.35 & -0.37 & 0.017 \\
\hline Implementation & -0.22 & 0.250 & 0.174 \\
\hline Total scores & $\mathbf{0 . 9 7}$ & $\mathbf{1 . 0 5}$ & $\mathbf{1 . 8 5}$ \\
\hline
\end{tabular}

Over the term of the first year course there were significant improvements in the results at the Problem Definition and Validation and Documentation categories. Interestingly the most significant gains on the survey correlate well with the process steps emphasized in the 
first year course. The importance of information gathering in the Problem Definition stage was emphasized both in the introductory design session and in a session devoted to information management run by the Engineering Library.

One confounding factor is that those who completed the post100 survey were somewhat self-selected. As mentioned above, the post-course survey in APSC-100 was conducted in team meetings since there was no class at the end of the course in which to conduct the survey. All students in APSC-100 are assessed by their upper year project manager on five criteria, allowing the grades of students who completed the design survey to be compared with those who did not. Those who completed the post survey had a slightly higher mean mark on their individual assessment by their project manager. In future years a post-project culminating activity is planned that will allow the post-survey to be conducted under similar conditions to the pre-survey.

There are significant gains between the end of the first year design course (post100) and the beginning of the third year design course (pre381) in Table 3. However, the data in this table should be treated cautiously, as two very different groups of students are being compared; the first year students includes all students coming into engineering, while the third year group is a self-selected group of students who have chosen to take an elective course in design tools and methodologies. As a result, it is not possible to authoritatively attribute the increase in score between the end of first year and the beginning of third year to improvement in understanding of engineering design across the entire general student body. This confounding influence may be controlled in future years by sampling a control group of students in third year who have not opted to take the elective design course.

The most significant gains in this study occur over the term of the third year design tools and methodology course. The score in each category increases, though the increase in Problem Definition and Validation and Documentation are not statistically significant. The most significant increases are in the Conceptual Design, Preliminary Design, and Detailed Design categories. This is an interesting result. While APSC 381 class instruction attempts to cover the broad range of engineering design process from problem definition through to implementation, the concurrent project ends at the detailed (paper) design stage due to the 12 week course duration. The survey results imply that deeper, retained learning (that which is statistically significant in the survey) is achieved through application of the instructional materials to the project. This is consistent with many previous educational studies. The later stages of validation and implementation, while discussed in class, are not "experienced" in the project, and therefore are not retained as well.
It may be argued that the absence of a significant increase in Problem Definition skills may due to the fact that by the start of third year, most students (and particularly those who self-select elective design courses) are already relatively competent in this phase due to previous experience.

\section{Conclusions}

This work developed a simple open-ended survey that identified improvements in students' ability to apply knowledge of a design process to design scenarios. A simple rubric was developed to score the surveys and used reliably by a non-expert with limited explanation.

Analysis of student scores on the survey indicates that first year students improved most significantly in their ability to define a problem and identify information necessary to solving the problem. Third year students were observed to have significant improvements in Conceptual Design, Preliminary Design, and Detailed Design, but not in later stages of the design, reflecting the activities which students "experience" in their course design projects.

Although the confounding influence of other courses and experiences was not assessed directly, the two courses discussed here are the most significant design experiences in the years during which the majority of students would take them.

\subsection{Next steps}

It is critical to validate this survey by comparing student scores on the survey to their performance in design activities. This will also be useful as a supplementary study of the correlation between design process and product.

In future years, several improvements to the survey are planned based on analysis of the results and discussion:

- The instructions on the survey will be changed slightly to state that students should give specific steps and tools that they would use to solve the design problem. It was felt that some students gave a very broad overview though they were capable of more.

- The conditions under which survey the survey was taken will be unified. This will reduce the impact of other factors on the results, and increase the proportion of first year students who do the survey.

- The survey will be run toward the end of the course, but not on the final day to reduce the impact of the end-of-term lethargy. 
Table 3: Design skill assessment rubric. 
It is hoped that the tool can be administered to a thirdyear control group not taking the multidisciplinary design course to allow assessment of design skill development between first and third year, and to compare the development of design capability between the two groups of students.

The survey will also be used to assess students in fourth year multidisciplinary design course that includes prototyping to see if the experience of prototyping results in gains on the survey in the later stages of the process. It is hoped that the tools can also be used to assess design learning in traditional capstone courses.

\section{Acknowledgements}

The authors would like to acknowledge the work of Anne-Marie Pap in scoring the design surveys and providing helpful feedback on the rubric. We would also like to thank our students for volunteering their time and effort to contribute to this study.

\section{References}

[1] C. J. Atman, J.R. Chimka, K.M. Bursic, and H.N.

Nachtmann. "A comparison of freshman and senior engineering design processes”, Design Studies 20 (2), pp. 131-152, 1999.

[2] Judith E. Sims-Knight, Richard L. Upchurch, and Paul Fortier, "Assessing Students' Knowledge of Design Process in a Design Task", Frontiers in Education, Indianapolis, IN, 2005

[3] Sims-Knight, J. Upchurch, R. Pendergrass, N. Meressi, T. Fortier, P. , "Assessing design by design: progress report 1", Frontiers in Education, 2003, 5-8 Nov. 2003

[4] J. Light, R. Korte, K. Yasuhara, D. Kilgore, "Exploring the relationships among performance on engineering tasks", confidence, gender, and first year persistence, 2007 ASEE Annual General Conference

[5] R. Bailey, Z. Szabo, "Assessing Engineering Design Process Knowledge”, Int. J. Engng Ed. Vol. 22, No. 3, pp. 508-518, 2006

[6] Radcliffe, David F; Lee, Tat Y., "Design methods used by undergraduate engineering students", Design Studies, Vol: 10, Issue: 4, October, 1989, pp. 199-207

[7] B. Frank, "Impact of Peer-Managed Project-Based Learning in First Year Engineering", ASEE Annual General Conference, June 2008

[8] D. Strong and S. Fostaty Young, "Effectively Assessing Professional Engineering Skills", Proceedings from the Canadian Design Engineering Network (CDEN) Conference, Winnipeg, Canada, 2007 